\title{
Development and Feasibility of an App to Decrease Risk Factors for Type 2 Diabetes in Hispanic Women With Recent Gestational Diabetes (Hola Bebé, Adiós Diabetes): Pilot Pre-Post Study
}

Ellen W Seely ${ }^{1}$, MD; Patricia Flynn Weitzman ${ }^{2}, \mathrm{PhD}$; Dharma Cortes ${ }^{2}, \mathrm{PhD}$; Sara Romero Vicente ${ }^{2}$, BSc; Sue E Levkoff ${ }^{2,3}, \mathrm{ScD}, \mathrm{MSW}, \mathrm{SM}$

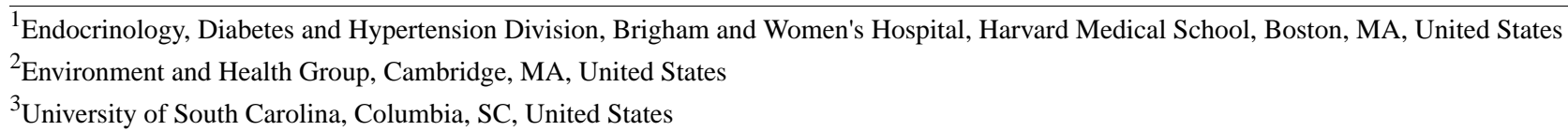

\section{Corresponding Author:}

Ellen W Seely, MD

Endocrinology, Diabetes and Hypertension Division

Brigham and Women's Hospital

Harvard Medical School

221 Longwood Ave

Boston, MA, 02115

United States

Phone: 16177325012

Email: eseely@bwh.harvard.edu

\section{Abstract}

Background: Hispanic women have increased risk of gestational diabetes mellitus (GDM), which carries an increased risk for future type 2 diabetes, compared to non-Hispanic women. In addition, Hispanic women are less likely to engage in healthy eating and physical activity, which are both risk factors for type 2 diabetes. Supporting patients to engage in healthy lifestyle behaviors through mobile health (mHealth) interventions is increasingly recognized as a viable, underused tool for disease prevention, as they reduce barriers to access frequently experienced in face-to-face interventions. Despite the high percentage of smartphone ownership among Hispanics, mHealth programs to reduce risk factors for type 2 diabetes in Hispanic women with prior GDM are lacking.

Objective: This study aimed to (1) develop a mobile app (¡Hola Bebé, Adiós Diabetes!) to pilot test a culturally tailored, bilingual (Spanish/English) lifestyle program to reduce risk factors for type 2 diabetes in Hispanic women with GDM in the prior 5 years; (2) examine the acceptability and usability of the app; and (3) assess the short-term effectiveness of the app in increasing self-efficacy for both healthy eating and physical activity, and in decreasing weight.

Methods: Social cognitive theory provided the framework for the study. A prototype app was developed based on prior research and cultural tailoring of content. Features included educational audiovisual modules on healthy eating and physical activity; personal action plans; motivational text messages; weight tracking; user-friendly, easy-to-follow recipes; directions on building a balanced plate; and tiered badges to reward achievements. Perceptions of the app's acceptability and usability were explored through four focus groups. Short-term effectiveness of the app was tested in an 8-week single group pilot study.

Results: In total, 11 Hispanic women, receiving care at a federally qualified community health center, aged 18-45 years, and with GDM in the last 5 years, participated in four focus groups to evaluate the app's acceptability and usability. Participants found the following sections most useful: audiovisual modules, badges for completion of activities, weight-tracking graphics, and recipes. Suggested modifications included adjustments in phrasing, graphics, and a tiering system of badges. After app modifications, we conducted usability testing with 4 Hispanic women, with the key result being the suggestion for a "how-to tutorial." To assess short-term effectiveness, 21 Hispanic women with prior GDM participated in the pilot. There was a statistically significant improvement in both self-efficacy for physical activity $(P=.003)$ and self-efficacy for healthy eating $(P=.007)$. Weight decreased but not significantly. Backend process data revealed a high level of user engagement. 
Conclusions: These data support the app's acceptability, usability, and short-term effectiveness, suggesting that this mHealth program has the potential to fill the gap in care experienced by Hispanic women with prior GDM following pregnancy. Future studies are needed to determine the effectiveness of an enhanced app in a randomized controlled trial.

Trial Registration: ClinicalTrials.gov NCT04149054; https://clinicaltrials.gov/ct2/show/NCT04149054

(JMIR Form Res 2020;4(12):e19677) doi: 10.2196/19677

\section{KEYWORDS}

gestational diabetes mellitus; diabetes prevention; Hispanic; Latina; intervention; mobile apps; mHealth

\section{Introduction}

Gestational diabetes mellitus (GDM), defined as glucose intolerance diagnosed after the first trimester of pregnancy [1], occurs in $3 \%-7 \%$ of pregnancies in the United States. Due, in part, to the fact that $40 \%$ of Hispanic women in the United States of child-bearing age are obese, and $51 \%$ experience excessive weight gain during pregnancy [2-5], this group has 1.5 times the risk of GDM compared to non-Hispanic White women [6]. GDM carries an overall increased risk as high as $60 \%$ for the development of type 2 diabetes mellitus (T2DM) [7], placing Hispanic women with prior GDM at high risk for future T2DM. Furthermore, obesity, a major risk factor for GDM and the strongest modifiable risk factor for T2DM, is more prevalent among Hispanic than non-Hispanic White women [8,9].

It is widely acknowledged that Hispanic women in the United States experience disparities in health care access and utilization compared to non-Hispanic women [10]. Cultural, social, and economic barriers also lead to disparities in healthy lifestyle behaviors [10]. Hispanic women face sociocultural barriers to healthy eating (eg, cost of healthy food, knowledge about nutritional values of some foods, and family food preferences) [11], as well as structural barriers (eg, food deserts) to obtaining healthy foods [12]. Hispanic women are also less likely to be physically active compared to non-Hispanic White women [13-15]. While some barriers to physical activity are comparable to those for non-Hispanic women (eg, lack of time, lack of childcare, being tired, and having limited self-discipline) [13]. Some additional barriers may be culturally influenced such as being discouraged by family members and friends, as well as environmental factors, such as not having a safe place to exercise [16].

The Diabetes Prevention Program (DPP), which was delivered as a face-to-face intervention, demonstrated that T2DM can be prevented by lifestyle changes focused on healthy eating and physical activity in women with a remote history of self-reported GDM [17]. The scalability of face-to-face DPP-based programs has been a challenge, due to the costs involved in implementing an in-person intervention and the difficulties encountered in attending face-to-face programs [18,19], particularly in postpartum women with recent GDM [20]. A potential approach to overcome barriers to face-to-face implementation is through mobile health (mHealth) technologies that can enable greater patient access.

According to the Pew Research Center, approximately $80 \%$ of the Hispanic population owns a smartphone, which is comparable to White and Black populations [21], with Hispanics more likely to use their smartphone to seek health information than their White counterparts [22]. Hispanic people in the United States spend more time using apps than the general population [23]. These data suggest that mobile apps are a viable, underused tool for T2DM prevention in minority populations including Hispanic women with recent GDM.

These findings led us to develop and pilot test a culturally tailored, bilingual (Spanish/English), mobile app-based lifestyle program, ¡Hola Bebé, Adiós Diabetes! (hereafter referred to as Hola Bebé), to reduce risk factors for T2DM in Hispanic women who have had GDM in the prior 5 years. The years after childbirth are well recognized as representing a "window of opportunity" to improve the future health of women who have had GDM, as demonstrated in our previous work [24,25] and by other studies [26,27]. The goal of the Hola Bebé pilot was to determine the feasibility, acceptability, and short-term effectiveness of an mHealth approach to increasing self-efficacy for healthy eating and increased physical activity, and promoting weight loss, in a population of Hispanic women with recent GDM.

\section{Methods}

\section{Overview}

Social cognitive theory (SCT) provided the framework for the Hola Bebé intervention. Self-efficacy, the belief in one's own capabilities to adopt and maintain behavior change [28,29], is a core component of SCT. For the intervention, we developed educational and motivational messages delivered through texts and videos to increase self-efficacy for healthy diet and physical activity. The focus on healthy eating and physical activity for the app was based on the DPP, which demonstrated that lifestyle change targeting healthy eating and increased physical activity led to a decrease in the development of T2DM in individuals at high risk for this condition including women with prior history of GDM [17]. Motivational messages were developed to target self-efficacy, which is associated with initiation and adherence to physical activity and other health-promoting activities [30,31]. Participants chose the times of day and frequency of the text messages. Cultural tailoring involved the development of the app first in Spanish, followed by translation into English with input from Hispanic women with a history of GDM who participated in every stage of app development.

The app included six educational audiovisual modules on healthy eating and physical activity; personal action plans for healthy eating and staying active; motivational and educational text messages; weight tracking; user-friendly, easy-to-follow recipes (Figure 1); directions on how to build a balanced plate; 
and tiered badges to reward achievements. For the action plans, participants were taught how to identify barriers to individualized goals and ways to overcome the barriers. Healthy eating advice was based on MyPlate [32]. Tiered badges could be earned by the participants with completion of a module,

Figure 1. Screenshots from the ¡Hola Bebé, Adiós Diabetes! app.

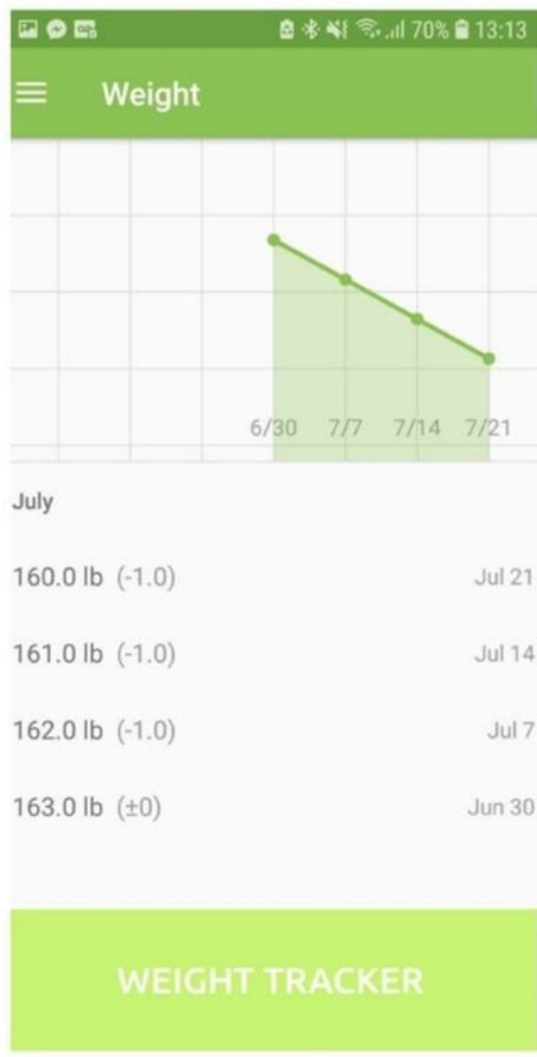

\section{Formative Phase}

In our formative work, we solicited feedback on the acceptability and usability of the mHealth program through four focus groups. Inclusion criteria included Hispanic women, aged 18-45 years, with prior GDM in the past 5 years, and who received medical care at a federally qualified community health center (CHC), a Level 3 Patient-Centered Medical Home in the Greater Boston area. In total, 11 women participated in the acceptability focus groups. Participants were asked for feedback on the prototype of the app, including what feature(s) they found most useful, preferences for phrasing, wording, graphics, colors, and type of badge tier system. The sections they found most useful were (1) the audiovisual modules, especially those about how to make healthy choices when eating out; (2) the badges for completion of activities; (3) the weight tracking graphic; and (4) the recipes. They also recommended a color scheme from a menu of options and offered suggestions for certain adjustments in phrasing and graphics. Finally, they suggested that the tiering system of action plan, and/or inputting of weight. The app was developed to meet the 8th-grade literacy level. All content was in plain-language Spanish and English, with Spanish and English audio voiceover.

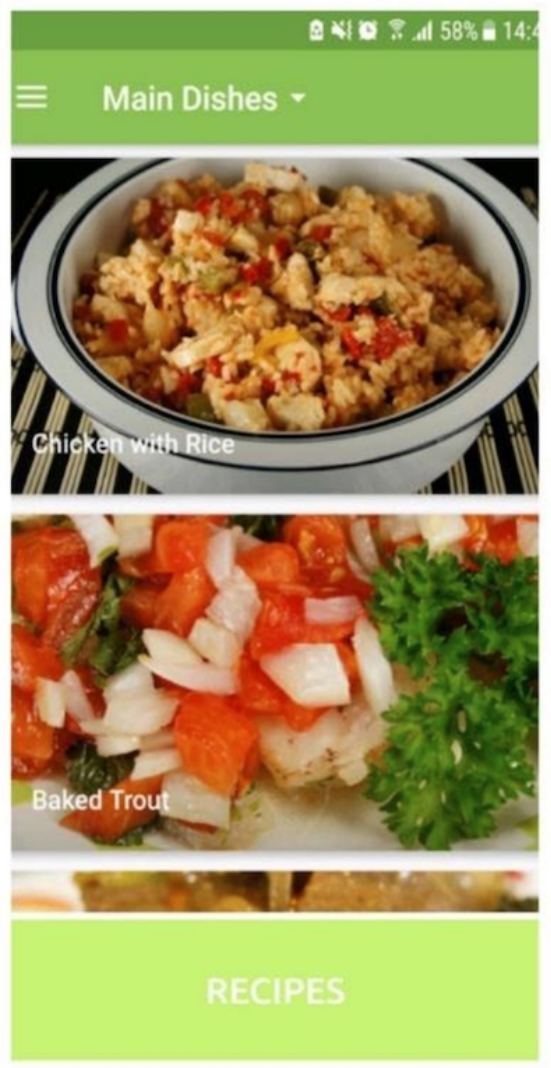

badges be based on a system of student achievement, such as "outstanding student" or "honor student."

After modifications to the prototype app were made based on participants' input, we conducted usability testing with 4 participants. Participants were given access to the app and asked to perform a number of tasks (eg, click on a tab, complete a module, and open an action plan tab), as well as to explore as they wished. The key result from the usability testing was that participants requested a "how-to tutorial" to make the app easier to use. Some, in fact, offered specific suggestions, such as "click here to add your weight." Participants also asked for more tabs to better label and access specific sections of the app. In addition, for the action plan completion section, participants suggested instead of only providing a free-text box, there be an additional drop down menu of action plan options with prepopulated action plans to choose from (eg, "I will balance my plate at dinner," "I will eat fruit and/or vegetable with every meal"). Feedback on the acceptability and usability was incorporated in the app prior to the pilot (Table 1). 
Table 1. Features of the ¡Hola Bebé, Adiós Diabetes! app.

\begin{tabular}{|c|c|}
\hline Domains & Features \\
\hline Healthy eating education and tools & $\begin{array}{l}\text { - Healthy eating educational audiovisual modules } \\
\text { - Healthy recipes } \\
\text { - } \quad \text { MyPlate education and demonstration } \\
\text { - }\end{array}$ \\
\hline Physical activity education and tools & $\begin{array}{l}\text { - } \quad \text { Physical activity educational audiovisual modules } \\
\text { - } \quad \text { Exercise videos } \\
\text { - } \quad \text { Action plans to stay active }\end{array}$ \\
\hline Text messaging & $\begin{array}{l}\text { - } \quad \text { Automated motivational text messages for healthy eating } \\
\text { - }\end{array}$ \\
\hline Self-monitoring & $\begin{array}{l}\text { - Weight tracking } \\
\text { - Gain badges by completing educational modules and action plans }\end{array}$ \\
\hline Social network & $\begin{array}{l}\text { - Sharing of experiences and recipes among participants through a community forum } \\
\text { - Asking questions of other participants through a community forum }\end{array}$ \\
\hline Operating system & - Android \\
\hline
\end{tabular}

\section{Pilot Trial}

A nurse and a medical assistant from the health center identified potential participants who were Hispanic and who had had GDM in the past 5 years from a list generated from the $\mathrm{CHC}$ database using the same inclusion criteria as in the formative phase. In addition, participants had to have or be willing to use an Android mobile phone for the study. For women with other smartphones, Android phones were offered on loan for the duration of the study. A member of the study team contacted those women who expressed interest in participating to provide additional information about the study. For those women who agreed to participate, the research assistant scheduled the first study visit. At the first study visit, informed written consent was obtained, and the participant's weight and height were determined by the research assistant. Weight was measured with the DR400C/Detecto Portable Home Health Care Scale, which was zeroed prior to each weight determination, with the participant wearing light clothes. Participants were asked to complete self-efficacy questionnaires for healthy eating (20 items) and physical activity (12 items) developed by Sallis et al [33], scored on a scale of $1-5$ with 5 being the most self-efficacious. These questionnaires have been widely used in research in both Spanish [34] and English. A research assistant helped the participants download (via the Google Play store) and open the app on their phone, and review the "how to use the app" tutorial. Participants were asked to watch one module weekly for the 8 weeks of study duration, complete the corresponding action plan, weigh themselves, and enter their weight into the app. At the end of the 8 weeks, baseline measures were repeated, and structured exit interviews, which focused on what participants liked best and areas for improvement, were performed. Primary outcomes included self-efficacy for healthy eating and self-efficacy for physical activity, with weight as a secondary outcome.

The study was approved by the Pearl Institutional Review Board and the board of the CHC. All participants signed written informed consent.

\section{Statistical Analysis}

Descriptive statistics were presented as mean (SD) and frequency $(\%)$. For pre-post comparisons from the pilot study, paired $t$ tests were conducted with a $5 \%$ significance level.

\section{Results}

In total, 30 eligible women were identified from the $\mathrm{CHC}$ database; 4 women could not be contacted. Of this, 26 women were successfully notified about the study and 21 (88\%) consented to participate. Reasons given for not participating included not being interested in participating $(n=3)$, moving out of state $(n=1)$, and not wanting to use a study-provided Android phone $(\mathrm{n}=1)$ (Table 2). At baseline, 21 participants were assessed and 18 completed the 8 -week study. 
Table 2. Baseline characteristics of the study population ( $\mathrm{N}=21)$.

\begin{tabular}{ll}
\hline Characteristic & Value \\
\hline Age (years), mean (SD) & $33(6.9)$ \\
Number of pregnancies, mean (SD) & $3(1.83)$ \\
Number of pregnancies with GDM ${ }^{\mathrm{a}}$, mean (SD) & $1(0.57)$ \\
Years post-GDM pregnancy, mean (SD) & $2.9(0.74)$ \\
Smartphone operating system, n (\%) & $14(66.6)$ \\
$\quad$ Android & $7(33.3)$ \\
$\quad$ OOS & $14(66.6)$ \\
Family history of diabetes in first-degree relative, $\mathrm{n}(\%)$ & $21(100)$ \\
Pthnicity: Hispanic, $\mathrm{n}(\%)$ & $21(100)$ \\
\hline
\end{tabular}

${ }^{\mathrm{a}} \mathrm{GDM}$ : gestational diabetes mellitus.

\section{Short-Term Effectiveness}

Self-efficacy for healthy eating increased from 4.2 (SD 0.8) to $4.4(0.7)(P=.007)$. Self-efficacy for physical activity increased from 3.0 (SD 0.6) to 3.4 (SD 0.6) $(P=.003)$. The secondary outcome, weight, fell from 163 (SD 36) to 162 (SD 37) lbs $(P=.16)$.

\section{Engagement}

Backend process data revealed a high level of user engagement. In total, 91\% (19/21) of participants viewed audiovisual modules and created action plans. There was also a high level of engagement in earning badges, with $95 \%$ of participants (20/21) earning badges by completing a learning module and/or an action plan or weighing. Participants posted tips on the community forum for other participants, such as a family recipe, and asked questions that other participants answered. One woman did not participate in any of the trackable app features.

\section{Exit Interviews}

We conducted exit interviews at the conclusion of the pilot study. The following quotes are representative of the participants' experiences of using the app:

No cambiaría nada de la aplicación, me gusta todo (I would not change anything from the app, I like everything).

Los videos de los módulos me han ayudado a entender la clase de alimentos que son buenos para mi. He comenzado a cambiar los granos por granos integrales y ahora me siento más saludable (The module videos helped me understand what kind of foods were good for me. I started changing my grains for whole wheat grains and now I feel healthier).

Cuando voy a comer con mi familia a un restaurante, ya sé que clase de comida puedo ordenar y no sentirme culpable después (Whenever I go to eat with my family to a restaurant, I know which kind of food I can order and not feel guilty afterwards).

Participants especially liked the personalized action plans, the motivational text messages, the at-home exercise videos, and the recipes. Women commented that they found the "how to use the app" tutorial to be helpful.

Participants had suggestions for incorporation in a future version of the app. They requested more exercise videos including Zumba and with the addition of music, expansion of the recipe section to include more Latin American dishes and vegetarian options, and explanation of portion sizes for each recipe that align with MyPlate. Women also requested videos for recipe preparation. Participants asked for an "ask the expert" option to submit specific exercise and diet questions on the community forum. The 7 iPhone users asked that an app be developed for use on an iPhone.

\section{Discussion}

\section{Principal Findings}

The ¡Hola Bebé, Adiós Diabetes! mHealth program was designed to overcome access barriers to T2DM prevention support among Hispanic women with prior GDM. Pilot testing indicated that it was well accepted, usable, and showed preliminary effectiveness at increasing self-efficacy for both physical activity and healthy eating. Weight decreased over the 8-week period but not significantly.

Interventions delivered through apps have great potential to fill the gap experienced by individuals seeking care across a range of conditions. A classification scheme for analyzing apps for preventing and managing disease proposes three dimensions for analysis: health condition (physical versus mental); prevention versus management; and, according to Green and Kreuter's [35] Precede-Proceed Model, predisposing, enabling, and motivating factors [36]. Using this classification scheme, Hola Bebé, addresses a physical condition, that of GDM, for the prevention of type 2 diabetes, and includes factors related to all aspects of the model, such as predisposing (eg, educational audiovisual modules, healthy recipes), enabling (eg, MyPlate demonstrations, action plans, weight tracking, and badges), and motivational (motivational text messages, sharing experiences/recipes, and asking questions through a community forum). 
Hola Bebé has the potential to fill the gap in care experienced by women with GDM following pregnancy. Over $86 \%$ of women with GDM have no contact with primary care in the first year post delivery, and close to $60 \%$ have no contact at 3 years post delivery [37]. This is despite recommendations from the American College of Obstetricians and Gynecologists [38] for referral to primary care and counseling for lifestyle modification in nutrition and exercise for women with a prior pregnancy complicated by GDM. Some have characterized women with prior GDM as falling into a "healthcare chasm" [39]; alternatively, others have referred to this more positively as "a fixable gap in women's preventative healthcare" [37], which app technology can potentially address. A major advantage of an app-delivered program for Hispanic women is the widespread use of apps by this population [40], which experiences significant disparities in health care [10]. Additional strengths of using an app for behavior change include easy access potential for integration with other apps that commonly come with smartphones (eg, pedometer and music apps); faster speed, as data are stored on the smartphone; and the ease of receiving notifications.

Importantly, Hola Bebé takes advantage of the "window of opportunity" following a complicated pregnancy by bridging the gap in care through lifestyle counseling without dependency on visits to the health center and clinician [37]. This app also overcomes many barriers experienced by women who have young children at home and competing priorities for time; it can be used at home or work or while traveling, day or night, and in small doses whenever users have a few minutes. In addition, this app was culturally and linguistically tailored for Hispanic women and was developed first in Spanish. Finally, the app was designed through an iterative approach incorporating feedback from Hispanic women with recent gestational diabetes at several stages of development.

\section{Limitations}

Given the nature of the pilot study, we were limited by a small sample size, lack of a control group, and short study duration. A further limitation was the unavailability of the app for iOS users.

\section{Conclusions}

The widespread use of apps among Hispanic women of childbearing age holds promise for this particularly high-risk and underserved population to reduce risk factors for diabetes. This app-delivered program should be tested in a randomized controlled trial and be developed for iOS users.

\section{Acknowledgments}

This study was supported by a funding (2R44MD009454-03) from the National Institute on Minority Health and Health Disparities (NIMHD), the National Institutes of Health (NIH).

\section{Conflicts of Interest}

None declared.

\section{References}

1. American Diabetes Association. Management of Diabetes in Pregnancy: Standards of Medical Care in Diabetes-2020. Diabetes Care 2020 Jan;43(Suppl 1):S183-S192. [doi: 10.2337/dc20-S014] [Medline: 31862757]

2. Headen IE, Davis EM, Mujahid MS, Abrams B. Racial-ethnic differences in pregnancy-related weight. Adv Nutr 2012 Jan;3(1):83-94 [FREE Full text] [doi: 10.3945/an.111.000984] [Medline: 22332106]

3. Chasan-Taber L, Schmidt MD, Pekow P, Sternfeld B, Solomon CG, Markenson G. Predictors of excessive and inadequate gestational weight gain in Hispanic women. Obesity (Silver Spring) 2008 Jul;16(7):1657-1666 [FREE Full text] [doi: 10.1038/oby.2008.256] [Medline: 18451771]

4. Brawarsky P, Stotland NE, Jackson RA, Fuentes-Afflick E, Escobar GJ, Rubashkin N, et al. Pre-pregnancy and pregnancy-related factors and the risk of excessive or inadequate gestational weight gain. Int J Gynaecol Obstet 2005 Nov;91(2):125-131. [doi: 10.1016/j.ijgo.2005.08.008] [Medline: 16202415]

5. Walker LO, Hoke MM, Brown A. Risk factors for excessive or inadequate gestational weight gain among Hispanic women in a U.S.-Mexico border state. J Obstet Gynecol Neonatal Nurs 2009;38(4):418-429. [doi: 10.1111/j.1552-6909.2009.01036.x] [Medline: 19614877]

6. Casagrande SS, Linder B, Cowie CC. Prevalence of gestational diabetes and subsequent Type 2 diabetes among U.S. women. Diabetes Res Clin Pract 2018 Jul;141:200-208. [doi: 10.1016/j.diabres.2018.05.010] [Medline: 29772286]

7. Kim C, Newton KM, Knopp RH. Gestational diabetes and the incidence of type 2 diabetes: a systematic review. Diabetes Care 2002 Oct;25(10):1862-1868. [doi: 10.2337/diacare.25.10.1862] [Medline: 12351492]

8. Flegal KM, Carroll MD, Kit BK, Ogden CL. Prevalence of obesity and trends in the distribution of body mass index among US adults, 1999-2010. JAMA 2012 Feb 1;307(5):491-497. [doi: 10.1001/jama.2012.39] [Medline: 22253363]

9. Obesity and Hispanic Americans. HHS.gov. 2020 Mar 26. URL: https://minorityhealth.hhs.gov/omh/browse.aspx?lvl=4 [accessed 2020-10-29]

10. Paz K, Massey KP. Health Disparity among Latina Women: Comparison with Non-Latina Women. Clin Med Insights Womens Health 2016;9(Suppl 1):71-74 [FREE Full text] [doi: 10.4137/CMWH.S38488] [Medline: 27478393] 
11. Cortés DE, Millán-Ferro A, Schneider K, Vega RR, Caballero AE. Food purchasing selection among low-income, Spanish-speaking Latinos. Am J Prev Med 2013 Mar;44(3 Suppl 3):S267-S273 [FREE Full text] [doi: 10.1016/j.amepre.2012.11.012] [Medline: 23415192]

12. Morrill KE, Lopez-Pentecost M, Ballesteros G, Pfander JL, Hingle MD, Klimentidis YC, et al. Weight loss interventions for Hispanic women in the USA: a protocol for a systematic review. Syst Rev 2019 Dec 01;8(1):301 [FREE Full text] [doi: 10.1186/s13643-019-1213-3] [Medline: $\underline{\text { 31787110] }}$

13. Bautista L, Reininger B, Gay JL, Barroso CS, McCormick JB. Perceived barriers to exercise in Hispanic adults by level of activity. J Phys Act Health 2011 Sep;8(7):916-925 [FREE Full text] [doi: 10.1123/jpah.8.7.916] [Medline: 21885882]

14. Neighbors CJ, Marquez DX, Marcus BH. Leisure-time physical activity disparities among Hispanic subgroups in the United States. Am J Public Health 2008 Aug;98(8):1460-1464. [doi: 10.2105/AJPH.2006.096982] [Medline: 18048795]

15. Centers for Disease ControlPrevention (CDC). Prevalence of regular physical activity among adults--United States, 2001 and 2005. MMWR Morb Mortal Wkly Rep 2007 Nov 23;56(46):1209-1212 [FREE Full text] [Medline: 18030281]

16. Larsen BA, Pekmezi D, Marquez B, Benitez TJ, Marcus BH. Physical activity in Latinas: social and environmental influences. Womens Health (Lond Engl) 2013 Mar;9(2):201-210 [FREE Full text] [doi: 10.2217/whe.13.9] [Medline: 23477325]

17. Ratner RE, Christophi CA, Metzger BE, Dabelea D, Bennett PH, Pi-Sunyer X, Diabetes Prevention Program Research Group. Prevention of diabetes in women with a history of gestational diabetes: effects of metformin and lifestyle interventions. J Clin Endocrinol Metab 2008 Dec;93(12):4774-4779 [FREE Full text] [doi: 10.1210/jc.2008-0772] [Medline: 18826999]

18. Hernan WH, Brandle M, Zhang P, Williamson DF, Matulik MJ, Ratner RE, Diabetes Prevention Program Research Group. Costs associated with the primary prevention of type 2 diabetes mellitus in the diabetes prevention program. Diabetes Care 2003 Jan;26(1):36-47 [FREE Full text] [doi: 10.2337/diacare.26.1.36] [Medline: 12502656]

19. Ackermann RT, Finch EA, Brizendine E, Zhou H, Marrero DG. Translating the Diabetes Prevention Program into the community. The DEPLOY Pilot Study. Am J Prev Med 2008 Oct;35(4):357-363 [FREE Full text] [doi: 10.1016/j.amepre.2008.06.035] [Medline: 18779029]

20. Nicklas JM, Zera CA, Seely EW, Abdul-Rahim ZS, Rudloff ND, Levkoff SE. Identifying postpartum intervention approaches to prevent type 2 diabetes in women with a history of gestational diabetes. BMC Pregnancy Childbirth 2011;11:23 [FREE Full text] [doi: $\underline{10.1186 / 1471-2393-11-23}$ ] [Medline: $\underline{21435246}$ ]

21. Perrin A, Turner E. Smartphones help blacks, Hispanics bridge some-but not all- digital gaps with whites. Pew Research Center. 2019. URL: https://www.pewresearch.org/fact-tank/2019/08/20/smartphones-help-blacks-hispanics-

bridge-some-but-not-all-digital-gaps-with-whites/ [accessed 2020-04-22]

22. Anderson M. Racial and ethnic differences in how people use mobile technology. Pew Research Center. 2015. URL: https:/ /www.pewresearch.org/fact-tank/2015/04/30/racial-and-ethnic-differences-in-how-people-use-mobile-technology [accessed 2020-04-22]

23. Descubrimiento Digital: The Online Lives of Latinx Consumers (Rep). The Nielsen Company. 2018. URL: https://www. nielsen.com/wp-content/uploads/sites/3/2019/04/the-online-lives-latinx-consumers.pdf [accessed 2020-10-28]

24. Bentley-Lewis R, Levkoff S, Stuebe A, Seely EW. Gestational diabetes mellitus: postpartum opportunities for the diagnosis and prevention of type 2 diabetes mellitus. Nat Clin Pract Endocrinol Metab 2008 Oct;4(10):552-558 [FREE Full text] [doi: 10.1038/ncpendmet0965] [Medline: 18779843]

25. Rich-Edwards JW, McElrath TF, Karumanchi SA, Seely EW. Breathing life into the lifecourse approach: pregnancy history and cardiovascular disease in women. Hypertension 2010 Sep;56(3):331-334 [FREE Full text] [doi:

10.1161/HYPERTENSIONAHA.110.156810] [Medline: 20679178]

26. Beckles G, Thompson-Reid P. Diabetes \& Women's Health across the Life Stages: A Public Health Perspective. Atlanta, GA: US Dept of Health and Human Services, Centers for Disease Control and Prevention; 2001.

27. Phelan S. Pregnancy: a "teachable moment" for weight control and obesity prevention. Am J Obstet Gynecol 2010 Feb;202(2):135.e1-135.e8 [FREE Full text] [doi: 10.1016/j.ajog.2009.06.008] [Medline: 19683692]

28. Bandura A. Self-efficacy: The Exercise of Control. New York, NY: WH Freeman/Times Books/Henry Holt \& Co; 1997.

29. Bandura A. The Explanatory and Predictive Scope of Self-Efficacy Theory. Journal of Social and Clinical Psychology 1986 Sep;4(3):359-373. [doi: 10.1521/jscp.1986.4.3.359]

30. Desharnais R, Bouillon J, Godin G. Self-efficacy and outcome expectations as determinants of exercise adherence. Psychol Rep 2016 Sep 01;59(3):1155-1159. [doi: 10.2466/pr0.1986.59.3.1155]

31. Nansel TR, Haynie DL, Lipsky LM, Wang J, Mehta SN, Laffel LM. Relationships among parent and youth healthful eating attitudes and youth dietary intake in a cross-sectional study of youth with type 1 diabetes. Int J Behav Nutr Phys Act 2013;10(1):125. [doi: 10.1186/1479-5868-10-125]

32. What is MyPlate? Chose MyPlate, US Department of Agriculture. 2020. URL: https://www.choosemyplate.gov/eathealthy/ WhatIsMyPlate [accessed 2020-12-18]

33. Sallis JF, Pinski RB, Grossman RM, Patterson TL, Nader PR. The development of self-efficacy scales for healthrelated diet and exercise behaviors. Health Educ Res 1988;3(3):283-292. [doi: 10.1093/her/3.3.283]

34. Sallis JF. Self-Efficacy for Diet and Exercise. DrJimSallis.org. URL: https://drjimsallis.org/measure selfefficacy.html [accessed 2020-10-28] 
35. Green LW, Kreuter MW. Health promotion planning: An educational and environmental approach. New York: McGraw-Hill Humanities; 2004.

36. Wang A, An N, Lu X, Chen H, Li C, Levkoff S. A classification scheme for analyzing mobile apps used to prevent and manage disease in late life. JMIR Mhealth Uhealth 2014 Feb 17;2(1):e6 [FREE Full text] [doi: 10.2196/mhealth.2877] [Medline: 25098687]

37. Bernstein JA, Quinn E, Ameli O, Craig M, Heeren T, Lee-Parritz A, et al. Follow-up after gestational diabetes: a fixable gap in women's preventive healthcare. BMJ Open Diabetes Res Care 2017;5(1):e000445 [FREE Full text] [doi: 10.1136/bmjdrc-2017-000445] [Medline: 28948028]

38. Committee on Practice Bulletins-Obstetrics. Practice Bulletin No. 180: Gestational Diabetes Mellitus. Obstet Gynecol 2017 Jul;130(1):e17-e37. [doi: 10.1097/AOG.0000000000002159] [Medline: 28644336]

39. Wilkinson SA, Lim SS, Upham S, Pennington A, O'Reilly SL, Asproloupos D, et al. Who's responsible for the care of women during and after a pregnancy affected by gestational diabetes? Med J Aust 2014 Aug 04;201(3 Suppl):S78-S81. [doi: 10.5694/mja14.00251] [Medline: 25047889]

40. La Oportunidad Latinx: Cultural currency and the consumer journey. The Nielson Company. 2019. URL: https://www. nielsen.com/us/en/insights/report/2019/la-oportunidad-latinx/ [accessed 2020-04-22]

\author{
Abbreviations \\ CHC: community health center \\ DPP: Diabetes Prevention Program \\ GDM: gestational diabetes mellitus \\ mHealth: mobile health \\ SCT: social cognitive theory \\ T2DM: type 2 diabetes mellitus
}

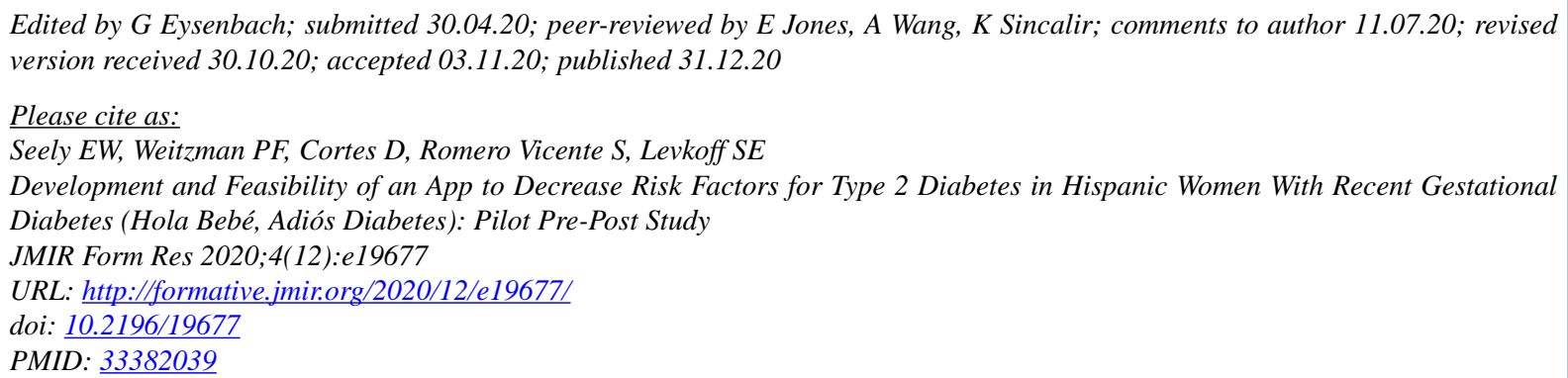

(CEllen W Seely, Patricia Flynn Weitzman, Dharma Cortes, Sara Romero Vicente, Sue E Levkoff. Originally published in JMIR Formative Research (http://formative.jmir.org), 31.12.2020. This is an open-access article distributed under the terms of the Creative Commons Attribution License (https://creativecommons.org/licenses/by/4.0/), which permits unrestricted use, distribution, and reproduction in any medium, provided the original work, first published in JMIR Formative Research, is properly cited. The complete bibliographic information, a link to the original publication on http://formative.jmir.org, as well as this copyright and license information must be included. 